\title{
REG $l \alpha$ is a biomarker for predicting response to chemotherapy with S-1 plus cisplatin in patients with unresectable stage IV gastric cancer
}

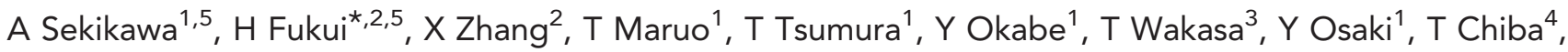

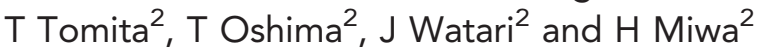 \\ ${ }^{1}$ Department of Gastroenterology and Hepatology, Osaka Red Cross Hospital, Osaka, Japan; ${ }^{2}$ Division of Upper \\ Gastroenterology, Department of Internal Medicine, Hyogo College of Medicine, I-1, Mukogawa, Nishinomiya 663-8501, Japan; \\ ${ }^{3}$ Department of Pathology, Osaka Red Cross Hospital, Osaka, Japan and ${ }^{4}$ Department of Gastroenterology and Hepatology, \\ Kyoto University Graduate School of Medicine, Kyoto, Japan
}

Background: The regenerating gene $1 \alpha$ (REG $\mid \alpha$ ) is involved in gastric carcinogenesis as an antiapoptotic factor. Therefore, we investigated whether REG $1 \alpha$ confers resistance to chemotherapeutic drugs in gastric cancer (GC) cells and whether REG I $\alpha$ expression is useful for predicting the response to chemotherapy and outcome in patients with GC.

Methods: A total of 70 patients with unresectable stage IV GC received first-line chemotherapy with S-1 and cisplatin (S-1/CDDP). The expression of REG $1 \alpha$ was evaluated immunohistochemically using biopsy samples obtained before chemotherapy, and its relationship to clinicopathological parameters was analysed statistically. The effects of REG la gene induction on resistance to 5-FU or CDDP treatment were examined by cell survival assay and flow cytometry.

Results: Of the 70 patients with unresectable stage IV GC, 19 (27\%) were positive for REG l $\alpha$ expression. The expression of REG I $\alpha$ was independently predictive of poorer progression-free and overall survival in such patients (hazard ratio (HR) 2.46; $P=0.002$ and HR 1.89; $P=0.037$, respectively). The gene induction of REG l $\alpha$ conferred resistance to cell death induced by 5-FU or CDDP in GC cells.

Conclusion: In patients with stage IV GC, REG I $\alpha$, which confers resistance to chemotherapeutic drugs in GC cells, is a potential biomarker for predicting resistance to S-1/CDDP treatment.

Gastric cancer (GC) is a major cause of cancer-related death worldwide (Kamangar et al, 2006; Ferlay et al, 2010), and the outcome of patients with unresectable GC is very poor (Chau et al, 2004; Lee et al, 2007). Recently, advances in chemotherapy have considerably improved the prognosis of patients with unresectable GC, and subsequently the combination of S-1 (comprising a prodrug of 5-fluorouracil, 5-chloro-2,4-dihydropyrimidine, and potassium oxonate) with cisplatin (S-1/CDDP) has been accepted as a first-line therapy for such patients in Japan (Boku, 2008; Koizumi et al, 2008; Ohtsu, 2008). However, the response to chemotherapy is known to differ widely among such patients, and in fact GC patients who show a poor response to first-line chemotherapy are considered to have a dismal prognosis (Matsubara et al, 2008; Choi et al, 2011; Park et al, 2011). In this

\footnotetext{
${ }^{*}$ Correspondence: Dr H Fukui; E-mail: hfukui@hyo-med.ac.jp
}

${ }^{5}$ These authors contributed equally to this work.

Received 11 September 2012; revised 2 November 2012; accepted 21 November 2012; published online 15 January 2013 
connection, reliable biomarkers that are able to predict the response to chemotherapy are urgently needed to improve the efficiency of chemotherapy for patients with unresectable GC.

The regenerating gene (Reg) was originally isolated from rat regenerating pancreatic islet cells (Terazono et al, 1988), and thereafter Reg was shown to have a trophic effect on gastric epithelial cells (Fukui et al, 1998). Recently, its human homologue, $R E G I \alpha$, was identified by microarray analysis as a gene distinctly overexpressed in GC tissues (Takaishi and Wang, 2007), and indeed several studies have indicated that REG I $\alpha$ is overexpressed in a subset of GC patients (Yonemura et al, 2003; Fukui et al, 2004; Yamagishi et al, 2009). Moreover, we have previously clarified that REG I $\alpha$ functions as an antiapoptotic factor in the development of GC (Sekikawa et al, 2005, 2008). These findings suggest that REG $\mathrm{I} \alpha$ plays a pivotal role in gastric carcinogenesis, and thus it is tempting to speculate that an antiapoptotic effect of REG I $\alpha$ may be associated with a poor response to chemotherapy in patients with GC. Therefore, in the present study we examined whether REG $\mathrm{I} \alpha$ is involved in acquisition of resistance to chemotherapeutic drugs in GC cells. Moreover, we aimed to clarify whether REG I $\alpha$ expression in biopsy samples before treatment could be a useful biomarker for predicting the response to chemotherapy and outcome in patients with unresectable GC.

\section{MATERIALS AND METHODS}

Patients, procedures, and tissue samples. A total of 70 patients who were diagnosed as having unresectable GC at Osaka Red Cross Hospital between 2007 and 2011 were enroled. Patients were eligible if they were diagnosed as having stage IV GC by oesophagogastroduodenoscopy (EGDS) and abdominopelvic computed tomography (CT), and moreover had histologically confirmed adenocarcinoma. Patients with recurrent gastric cancer or other malignancies and those who had received previous chemotherapy or radiotherapy were excluded. Patients with an Eastern Cooperative Oncology Group (ECOG) performance status of 3 or 4 and those without adequate organ function were also excluded. Stage classification was done in accordance with the criteria of the Japanese Gastric Cancer Association (Japanese Gastric Cancer Association, 1998).

All patients received first-line chemotherapy with S-1/CDDP for unresectable GC, as reported previously (Koizumi et al, 2008). Briefly, S-1 was given orally twice for the first 3 weeks of a 5-week cycle. The dose of S-1 administered each time was determined according to each patient's body surface area as follows: $<1.25 \mathrm{~m}^{2}$, $40 \mathrm{mg} ; 1.25-1.50 \mathrm{~m}^{2}, 50 \mathrm{mg}$; and $>1.5 \mathrm{~m}^{2}, 60 \mathrm{mg}$. Intravenous infusion of CDDP $\left(60 \mathrm{mg} \mathrm{m}^{-2}\right)$ was administrated on day 8 of each cycle. Treatment was repeated until one of the following occurred: progressive disease, unacceptable toxic side effect, and withdrawal of the patient's consent. If the S-1/CDDP chemotherapy failed, second-line chemotherapy was recommended for all patients if they had adequate organ function and performance status. Of the 70 patients, $49(70.0 \%)$ received second-line chemotherapy; 27 patients $(55.1 \%)$ were treated with irrinotecanbased regimens and $22(44.9 \%)$ were treated with taxane-based regimens. The patients who exchanged to second-line treatment without progressive disease because of adverse reactions were censored. To evaluate tumour responses to S-1/CDDP chemotherapy, tumours were measured after every two courses of chemotherapy using CT or MRI imaging. Tumour responses were classified according to the Response Evaluation Criteria for Solid Tumours (RECIST) (Therasse et al, 2000). The patients who had no measurable lesions were excluded. Progression-free survival (PFS) was defined as the time from the first day of chemotherapy to the date of onset of progressive disease during treatment with
S-1/CDDP or death from any cause. Overall survival (OS) was defined as time from the first day of chemotherapy to the date of death because of any cause.

The biopsy samples from GC tissues were obtained by EGDS before chemotherapy and examined for the study. The tissue samples were fixed in $10 \%$ formalin and embedded in paraffin. Multiple haematoxylin-eosin-stained sections of all 70 lesions were examined. The tissue sections were also subjected to immunostaining. The following factors were determined for all patients and lesions: age, gender, performance status, tumour location, macroscopic type, Lauren's histological classification, location of metastasis, number of metastatic organs, serum albumin, alkaline phosphatase, CEA, and CA19-9. The clinicopathological features of the patients are summarised in Table 1 .

This study was carried out with the approval of the Osaka Red Cross Hospital Ethical Committee, and informed consent was obtained from all patients.

Immunohistochemical staining. Immunohistochemical staining for REG I $\alpha$ was performed with a LSAB-2 kit (DAKO, Kyoto, Japan) as described previously (Yamagishi et al, 2009), using antihuman REG I $\alpha$ antibody (dilution $1: 1000$ ). The monoclonal antibody for human REG I $\alpha$ was generated against human REG I $\alpha$ corresponding to positions 23-166 of the deduced human REG I $\alpha$ (Watanabe et al, 1990). The specificity of the antibody was proven by not only western blot analysis (Watanabe et al, 1990) but also immunohistochemistry (Satomura et al, 1993). Finally, the sections were incubated in $3,3^{\prime}$-diaminobenzide tetrahydrochloride with $0.05 \% \mathrm{H}_{2} \mathrm{O}_{2}$ for $3 \mathrm{~min}$ and then counterstained with Mayer's haematoxylin. The percentage of cancer cells stained with anti-human REG I $\alpha$ antibody was evaluated. A specimen was considered positive when $>10 \%$ of cancer cells were stained. When $<10 \%$ of cancer cells were stained, immunostaining was considered negative. When multiple biopsy samples were obtained from the lesion, the patient was considered as positive if at least one sample is positive.

Transfection and expression of the human REG I $\alpha$ cDNA in gastric cancer cell line. A human gastric cancer cell line AGS was maintained routinely in Ham's F12 medium (Invitrogen, Grand Island, NY, USA) with $10 \%$ fetal bovine serum (Sigma Chemical Co., St Louis, MO, USA) in a humidified incubator at $37^{\circ} \mathrm{C}$ with an atmosphere of $5 \% \mathrm{CO}_{2}$.

The full-length human REG I $\alpha$ cDNA was inserted in the pIRES2-EGFP vector (Clontech, Palo Alto, CA, USA). The construct was named pIRES2-hREG I $\alpha$, and the pIRES2-EGFP vector without an insert was used as control. The AGS cells, stably transfected with pIRES2-hREG I $\alpha$ (AGS-REG I $\alpha$ ) or pIRES2-EGFP (AGS-EGFP) vectors, were prepared as previously described (Sekikawa et al, 2005).

Cell survival assay. 5-Fluorouracil (5-FU; Wako Pure Chemical Industries, Ltd, Osaka, Japan) and CDDP (Wako) were dissolved in dimethylsulphoxide and then diluted in culture medium for experiments. The AGS-REG I $\alpha$ cells or AGS-EGFP cells $\left(2 \times 10^{4}\right)$ were plated in 12-well microplates (IWAKI, Funabashi, Japan). The cells were then treated with 5-FU $(0.2-20 \mathrm{~mm})$ or CDDP $(1-100 \mu \mathrm{M})$ in serum-free medium for $30 \mathrm{~h}$. Thereafter, both floating and attached cells were collected, and the number of surviving cells was evaluated by Trypan blue exclusion.

Cell death assay. The AGS-REG I $\alpha$ cells or AGS-EGFP cells $\left(2.5 \times 10^{5}\right)$ were plated in $6 \mathrm{~cm}$ dishes (IWAKI). The cells were treated with 5 -FU or CDDP for $24 \mathrm{~h}$ and collected as described above. After washing with PBS, the cells were incubated with propidium iodide in binding buffer in accordance with the manufacturer's protocol. Stained cells were analysed on a FACScalibur flow cytometer (Becton Dickinson, Franklin Lakes, 


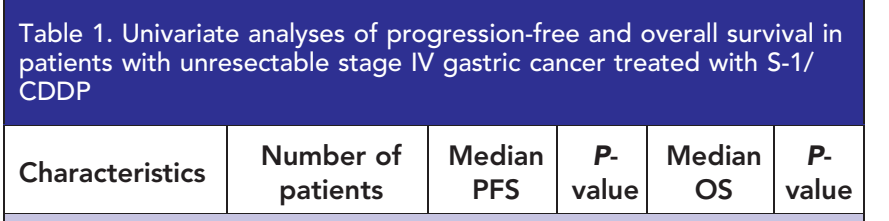

Age (years, range; 38-78)

\begin{tabular}{l|l|l|l|l|l|}
\hline \begin{tabular}{l|l|l|l|}
$\mid<0$ \\
$\geqslant 60$
\end{tabular} & $16(22.9 \%)$ & 4.0 & 0.667 & 10.0 & 0.112 \\
\hline Gender & $54.1 \%)$ & 5.8 & & 12.8 & \\
\hline Male & $48(68.6 \%)$ & 5.5 & 0.340 & 12.4 & 0.580 \\
Female & $22(31.4 \%)$ & 5.4 & & 10.3 & \\
\hline
\end{tabular}

Performance status

\begin{tabular}{|c|c|c|c|c|c|}
\hline $\begin{array}{l}0 \\
1-2\end{array}$ & $\begin{array}{l}53 \text { (75.7\%) } \\
17(24.3 \%)\end{array}$ & $\begin{array}{l}5.5 \\
5.4\end{array}$ & 0.261 & $\begin{array}{l}14.5 \\
10.4\end{array}$ & 0.284 \\
\hline \multicolumn{6}{|c|}{ Location } \\
\hline $\begin{array}{l}\text { Fundus } \\
\text { Antrum }\end{array}$ & $\begin{array}{l}50(71.4 \%) \\
20(28.6 \%)\end{array}$ & $\begin{array}{l}4.7 \\
6.0\end{array}$ & 0.986 & $\begin{array}{l}10.6 \\
14.6\end{array}$ & 0.145 \\
\hline
\end{tabular}

Macroscopic type

\begin{tabular}{|l|l|l|l|l|l|}
\hline Scirrhous & $13(18.6 \%)$ & 3.8 & 0.058 & 10.0 & 0.028 \\
Nonscirrhous & $57(81.4 \%)$ & 5.8 & & 12.4 & \\
\hline
\end{tabular}

Lauren's classification

\begin{tabular}{|l|l|l|l|l|l|}
\hline Intestinal & $34(48.6 \%)$ & 5.4 & 0.919 & 13.0 & 0.197 \\
Diffuse & $36(51.4 \%)$ & 5.4 & & 10.0 & \\
\hline
\end{tabular}

\section{Liver metastasis}

\begin{tabular}{|l|l|l|l|l|l|}
\hline Yes & $31(44.3 \%)$ & 4.8 & 0.136 & 10.2 & 0.176 \\
No & $39(55.7 \%)$ & 6.0 & & 13.0 & \\
\hline
\end{tabular}

\section{Peritoneal dissemination}

\begin{tabular}{|l|l|l|l|l|l|}
\hline $\begin{array}{l}\text { Yes } \\
\text { No }\end{array}$ & $31(44.3 \%)$ & 5.4 & 0.956 & 12.4 & 0.427 \\
$39(55.7 \%)$ & 5.5 & & 10.6 & \\
\hline \multicolumn{5}{|l|}{ Other metastasis } \\
\hline Yes & $17(24.3 \%)$ & 4.9 & 0.198 & 10.3 & 0.239 \\
No & $53(75.7 \%)$ & 5.7 & & 12.4 & \\
\hline
\end{tabular}

Number of metastatic organs

\begin{tabular}{|c|c|c|c|c|c|}
\hline $\begin{array}{l}\text { One } \\
\text { More than two }\end{array}$ & $\begin{array}{l}18 \text { (25.7\%) } \\
52 \text { (74.3\%) }\end{array}$ & $\begin{array}{l}6.3 \\
4.8\end{array}$ & 0.320 & $\begin{array}{l}12.8 \\
11.1\end{array}$ & 0.234 \\
\hline \multicolumn{6}{|c|}{ Albumin (mg dl ${ }^{-1}$, range; $2.2-4.6$ ) } \\
\hline $\begin{array}{l}<3.5 \\
\geqslant 3.5\end{array}$ & $\begin{array}{l}28(40.0 \%) \\
42(60.0 \%)\end{array}$ & $\begin{array}{l}4.1 \\
6.2\end{array}$ & 0.210 & $\begin{array}{l}10.2 \\
12.4\end{array}$ & 0.202 \\
\hline
\end{tabular}

ALP (IUI ${ }^{-1}$, range; 96-3696)

\begin{tabular}{|l|l|l|l|l|l|}
\hline$<339$ & $54(77.2 \%)$ & 5.5 & 0.828 & 12.4 & 0.968 \\
\hline 339 & $16(22.8 \%)$ & 6.0 & & 11.5 & \\
\hline
\end{tabular}

CEA $\left(\mathrm{mg} \mathrm{dl}^{-1}\right.$, range; $\left.1-8040\right)$

\begin{tabular}{|l|l|l|l|l|l|}
\hline$<5.0$ & $35(50.0 \%)$ & 5.8 & 0.690 & 13.0 & 0.572 \\
\hline$\geqslant 5.0$ & $35(50.0 \%)$ & 4.9 & & 11.1 & \\
\hline
\end{tabular}

CA19-9 $\left(\mathrm{mg} \mathrm{dl}^{-1}\right.$, range; 1-182 500)

\begin{tabular}{|l|l|l|l|l|l|}
\hline$<37$ & $40(57.4 \%)$ & 4.8 & 0.622 & 12.8 & 0.317 \\
\hline 37 & $30(42.6 \%)$ & 5.7 & & 10.2 & \\
\hline
\end{tabular}

Abbreviations: $\quad \mathrm{ALP}=$ alkaline phosphatase; $\quad \mathrm{CA}=$ carbohydrate antigen; $\mathrm{CEA}=$ carcinoembryonic antigen; $\mathrm{OS}=$ overall survival; $\mathrm{PFS}=$ progression-free survival; $\mathrm{S}-1$ / $\mathrm{CDDP}=\mathrm{S}-1$ and cisplatin
NJ, USA), and the data obtained were analysed using CELLQUEST software (Becton Dickinson).

Statistical analysis. Statview 5.0J statistical software (Abacus Concepts Inc., Berkeley, CA, USA) was used for all analyses. Cumulative survival rate was evaluated by the Kaplan-Meier method and analysed by the log-rank test. The $\chi^{2}$ analyses were performed to investigate the relationship between REG I $\alpha$ expression and clinicopathological features, and Fisher's exact analyses were also used, as necessary. Univariate and multivariate Cox regression analyses were used to examine whether REG I $\alpha$ expression was an independent predictor of PFS or OS. All values were expressed as the mean \pm s.e.m. The data for cell survival and death were analysed using unpaired two-tailed $t$-test. The $P$-values of $<0.05$ were considered to indicate statistical significance.

\section{RESULTS}

Outcome of first-line treatment with S-1/CDDP in patients with stage IV unresectable GC. A total of 348 cycles (median of 5.0 cycles for each patient (range 1-17)) of S-1/CDDP treatment were administered. Median follow-up period was 12.4 (mean 12.8; range 2-42) months. No treatment-related deaths were identified during the study. Among the 70 patients treated with S-1/CDDP, 2 (2.9\%) showed a complete response and 23 (33\%) showed a partial response, giving an overall response rate of $36 \%$. The median PFS and OS for the patients overall were 5.4 months (95\% CI, 4.8-6.2) and 12.3 months (95\% CI, 11.1-13.5), respectively (Supplementary Figure 1). Regarding the relationship between outcome and response to S-1/CDDP treatment, the median OS was significantly longer in responders (18.3 months, 95\% CI, 16.1-20.5) than in nonresponders (9.3 months, 95\% CI, 7.9-10.8, $P=0.0002$ ). These outcomes were consistent with previous reports describing S-1/CDDP treatment in patients with unresectable GC (Koizumi et al, 2008).

Relationship between PFS or OS and clinicopathological features. In patients with scirrhous-type GC, PFS tended to be shorter $(P=0.058$, Table 1$)$ and OS was significantly shorter $(P=0.028$, Table 1$)$ than those in patients with nonscirrhous-type GC. None of the other parameters, including age, gender, performance status, Lauren's classification, liver metastasis, peritoneal dissemination, number of metastatic organs, serum albumin, ALP, CEA, or CA19-9, had a significant relationship to PFS or OS (Table 1).

Relationship between REG I $\alpha$ expression and clinicopathological features in patients with unresectable GC. The expression of REG I $\alpha$ was evaluated immunohistochemically in biopsy samples from patients with unresectable GC before chemotherapy. Among the 70 patients examined, 19 (27\%) were positive for REG I $\alpha$ expression (Figure 1). Regarding the clinicopathological features in patients with stage IV GC, REG I $\alpha$ expression showed no relationship to any of the clinicopathological features investigated (Supplementary Table 1).

REG $I \alpha$ expression is predictive of response to S-1/CDDP treatment. We examined the relationship between REG I $\alpha$ expression in pretreatment biopsy samples and the subsequent response to S-1/CDDP treatment. Among the 19 patients with REG I $\alpha$-positive unresectable GC, only 1 (5\%) showed partial response to $\mathrm{S}-1 / \mathrm{CDDP}$ treatment, whereas the remaining 18 patients showed stable or progressive disease. In contrast, among the 51 REG I $\alpha$-negative patients, 2 had a complete response and 22 had a partial response; that is, $47 \%$ of REG $\mathrm{I} \alpha$-negative patients responded to S-1/CDDP treatment. The difference in response to S-1/CDDP treatment between the REG I $\alpha$-positive and REG I $\alpha$ negative groups was significant $(P=0.0084$; Table 2$)$. 

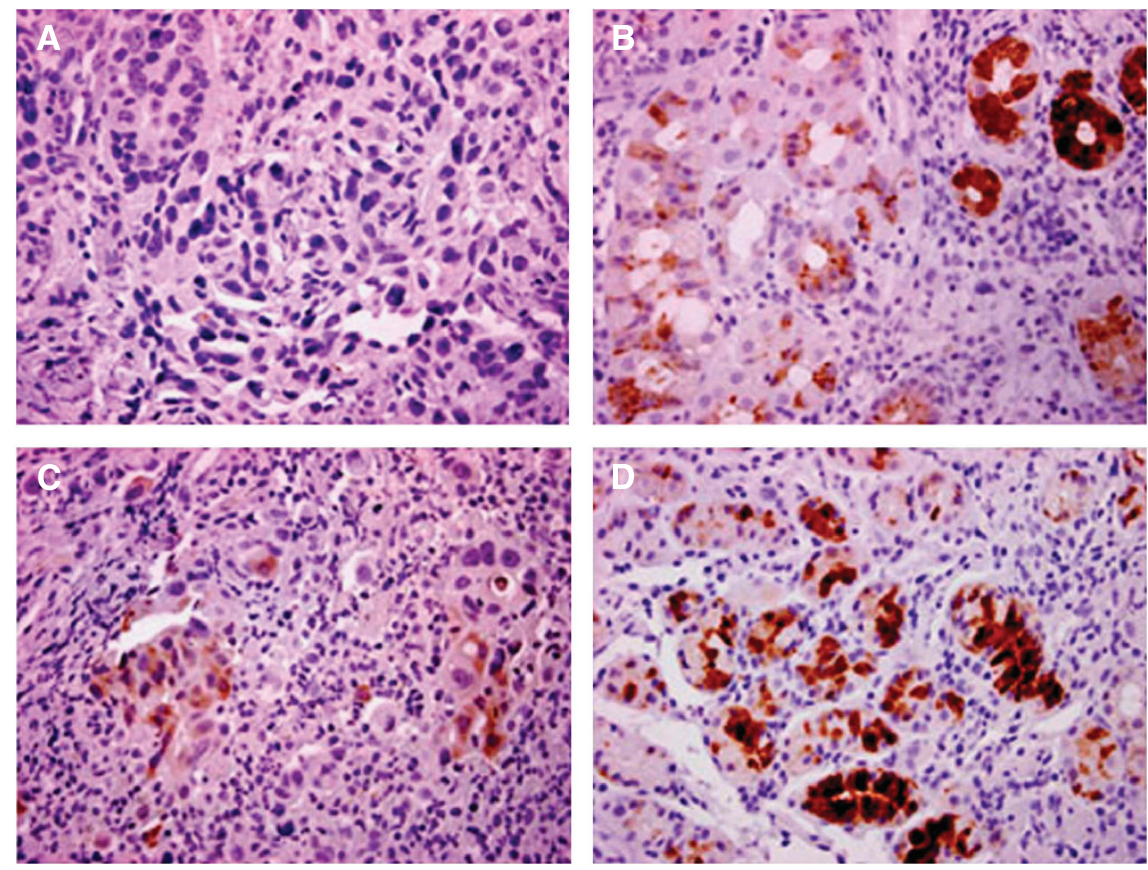

Figure 1. Immunostaining of REG $1 \alpha$ in biopsy samples obtained from gastric cancer tissues. The biopsy samples were obtained before chemotherapy (A, B, and D) and after disease progression (C). (A) The REG l $\alpha$-negative gastric cancer (diffuse type). (B) The REG l $\alpha$-positive gastric cancer (intestinal type). (C) The REG I $\alpha$-positive gastric cancer (diffuse type). This sample was obtained from the same patient as that in (A) when he developed disease progression after S-1/CDDP treatment. (D) The REG l $\alpha$-positive signet-ring cell carcinoma (diffuse type).

\begin{tabular}{|c|c|c|c|}
\hline \multicolumn{4}{|c|}{ REG I $\alpha$ expression } \\
\hline & Negative & Positive & $P$-value \\
\hline $\mathrm{CR}$ & 2 & 0 & \\
\hline$P R$ & 22 & 1 & 0.0084 \\
\hline SD & 13 & 6 & \\
\hline PD & 14 & 12 & \\
\hline
\end{tabular}

Moreover, we investigated whether the expression of REG I $\alpha$ changed in patients with unresectable GC after disease progression. Among the 10 patients whose GC had been negative for REG $\mathrm{I} \alpha$ before S-1/CDDP treatment, 8 became positive for REG I $\alpha$ after disease progression (Figure 1).

REG I $\alpha$ expression is prognostic for patients with unresectable GC treated with S-1/CDDP. To evaluate the prognostic significance of REG $I \alpha$ expression in patients treated with S-1/CDDP, we constructed Kaplan-Meier curves (Figure 2). The patients with REG I $\alpha$-positive GC had a significantly worse PFS than those without $(P=0.0004$, Figure $2 \mathrm{~A})$. In addition, the patients positive for REG I $\alpha$ had a significantly worse OS than those who were negative $(P=0.015$, Figure $2 \mathrm{~B})$.

To confirm whether GC patients are possible to be subdivided, we classified GC patients into four groups according to REG index in biopsy samples as follows: group $0(0 \%, n=37)$, group I $(1-9 \%$, $n=14)$, group II $(10-49 \%, n=12)$, and group III $(50-100 \%$, $n=7)$. The PFS and OS were not significantly different between group 0 and group I but those were significantly worse in group II than in group I $(P=0.015$ and 0.024 , respectively). On the other hand, PFS and OS were not significantly different between group II and group III, although these were significantly worse in group II/III than in group I ( $P=0.0005$ and 0.0261 , respectively).

We next examined whether REG $\mathrm{I} \alpha$ expression is an independent factor predictive of PFS and OS. Univariate analysis indicated that macroscopic type as well as REG I $\alpha$ expression was predictive of PFS in patients with unresectable GC after S-1/CDDP treatment $(P=0.058$ and 0.0004 , respectively). Furthermore, multivariate analysis revealed that REG $\mathrm{I} \alpha$ expression was an independent factor predictive of PFS in these patients $(P=0.002$, Table 3).

With regard to OS in the patients investigated, univariate analysis showed that macroscopic type and REG $\mathrm{I} \alpha$ expression were predictive factors. Similarly for PFS, multivariate analysis revealed that REG I $\alpha$ expression was an independent factor predictive of OS in patients with unresectable GC after S-1/CDDP treatment $(P=0.037$, Table 3$)$.

Although we performed multivariate analysis by adding two more categories (liver metastasis and other metastasis) in multivariate analysis for PFS, REG I $\alpha$ expression remained to be an independent factor predictive of PFS in patients with GC after S-1/CDDP treatment $(P=0.0075)$. On the other hand, we added two more categories (age and location) in multivariate analysis for OS. The expression of REG $\mathrm{I} \alpha$ was also an independent factor predictive of $O S$ in these patients $(P=0.047)$.

Effects of REG I $\alpha$ gene induction on resistance to anticancer drugs in GC cells. We next examined the effect of REG I $\alpha$ gene induction in GC cells treated with 5-FU or CDDP in terms of cell survival. The survival rate of gastric cancer cells decreased in a dose-dependent manner when they were treated with 5-FU or CDDP (Figure 3). Thus, the survival rate was significantly higher in the AGS-REG $I \alpha$ group than in the AGS-EGFP group when cells were treated with 5-FU at concentrations of $0.2-20 \mathrm{~mm}(P<0.001$, Figure $3 \mathrm{~A})$. Similarly, the survival rate was significantly higher in the AGS-REG I $\alpha$ group when treated with CDDP at concentrations of $1-100 \mu \mathrm{M}(P<0.001$, Figure $3 \mathrm{~B})$. Conversely, FACS analyses revealed that the number of propidium iodide-positive cells was significantly smaller in the AGS-REG $\mathrm{I} \alpha$ group than in the 

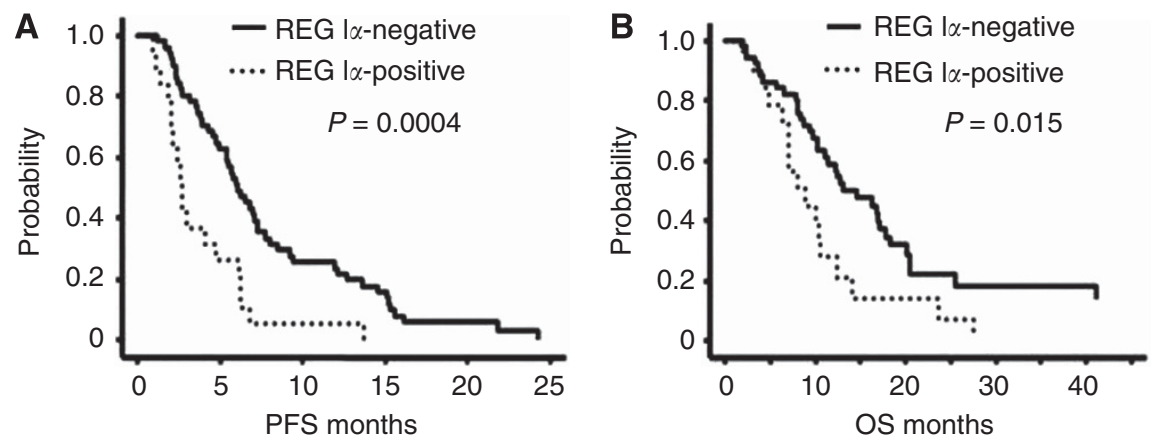

Figure 2. (A) Progression-free survival (PFS) and (B) overall survival (OS) according to REG I $\alpha$ expression in patients with unresectable stage IV GC who received first-line treatment with S-1/CDDP. Kaplan-Meier curves were constructed and pairwise differences were analysed by log-rank test.

Table 3. Univariate and multivariate analyses of progression-free and overall survival in patients with unresectable stage IV gastric cancer treated with S-1/CDDP

\begin{tabular}{|c|c|c|c|c|c|c|}
\hline & \multicolumn{3}{|c|}{ PFS } & \multicolumn{3}{|c|}{ os } \\
\hline & \multirow{2}{*}{$\begin{array}{c}\text { Univariate } \\
\boldsymbol{P} \text {-value }\end{array}$} & \multicolumn{2}{|c|}{ Multivariate } & Univariate & \multicolumn{2}{|c|}{ Multivariate } \\
\hline & & $95 \% \mathrm{Cl}$ & $\boldsymbol{P}$-value & $\boldsymbol{P}$-value & $95 \% \mathrm{Cl}$ & $P$-value \\
\hline \multicolumn{7}{|c|}{ Macroscopic type } \\
\hline $\begin{array}{l}\text { Nonscirrhous } \\
\text { Scirrhous }\end{array}$ & 0.058 & $\begin{array}{c}1 \\
1.52(0.81-2.87)\end{array}$ & 0.195 & 0.028 & $\begin{array}{c}1 \\
1.81(0.94-3.47)\end{array}$ & 0.075 \\
\hline \multicolumn{7}{|c|}{ REG $1 \alpha$ expression } \\
\hline $\begin{array}{l}\text { Negative } \\
\text { Positive }\end{array}$ & 0.0004 & $\begin{array}{c}1 \\
2.46(1.37-4.35)\end{array}$ & 0.002 & 0.015 & $\begin{array}{c}1 \\
1.89(1.04-3.44)\end{array}$ & 0.037 \\
\hline
\end{tabular}

A

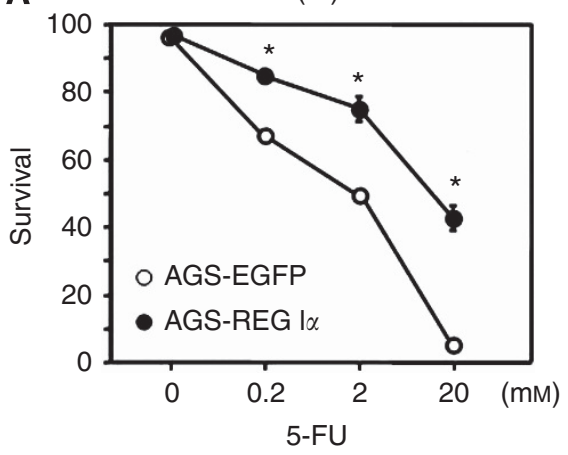

B

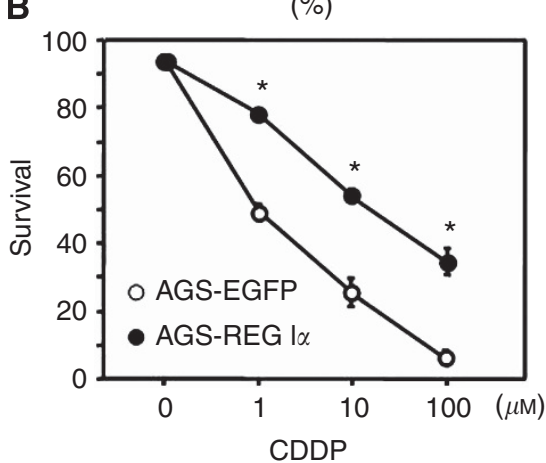

Figure 3. Effects of REG la gene induction on resistance to anticancer drugs in gastric cancer cells. Human gastric cancer AGS cells stably transfected with pIRES2-hREG I $\alpha$ (AGS-REG I $\alpha$ ) or pIRES2-EGFP (AGS-EGFP; control) plasmid were treated with 5-FU (A, 0.2-20 mM) or CDDP $(B, 1-100 \mu \mathrm{M})$ for $30 \mathrm{~h}$. The percentage of viable cells was then evaluated, as described in Materials and Methods. All results are expressed as the means \pm s.e.m. of four samples. ${ }^{\star} P<0.001$ vs AGS-EGFP at the same dose point.

AGS-EGFP group when cells were treated with 5-FU $(P<0.05$, Figure $4 \mathrm{~A}$ and $\mathrm{B})$ or $\mathrm{CDDP}(P<0.0001$, Figure $4 \mathrm{C}$ and $\mathrm{D})$, suggesting that induction of the REG I $\alpha$ gene played a role in conferring resistance to anticancer drug-induced cell death.

\section{DISCUSSION}

Recent studies have suggested that the tumour response to first-line chemotherapy is strongly correlated with PFS and/or OS in patients with unresectable GC (Ichikawa and Sasaki, 2006; Kodera et al, 2011). Supporting those data, the present study showed that not only PFS but also OS was significantly longer in responders to S-1/CDDP treatment than in nonresponders. Thus, the outcome in patients with unresectable GC is markedly dependent on the response to first-line chemotherapy. In this context, it is very important to identify biomarkers that can be used to predict the responses of such patients to first-line chemotherapy. Therefore, in the present study we investigated the expression of REG I $\alpha$ in biopsy samples before chemotherapy and subsequently showed that REG I $\alpha$ expression is a useful biomarker for predicting not only the response to S-1/CDDP treatment but also PFS and OS in 

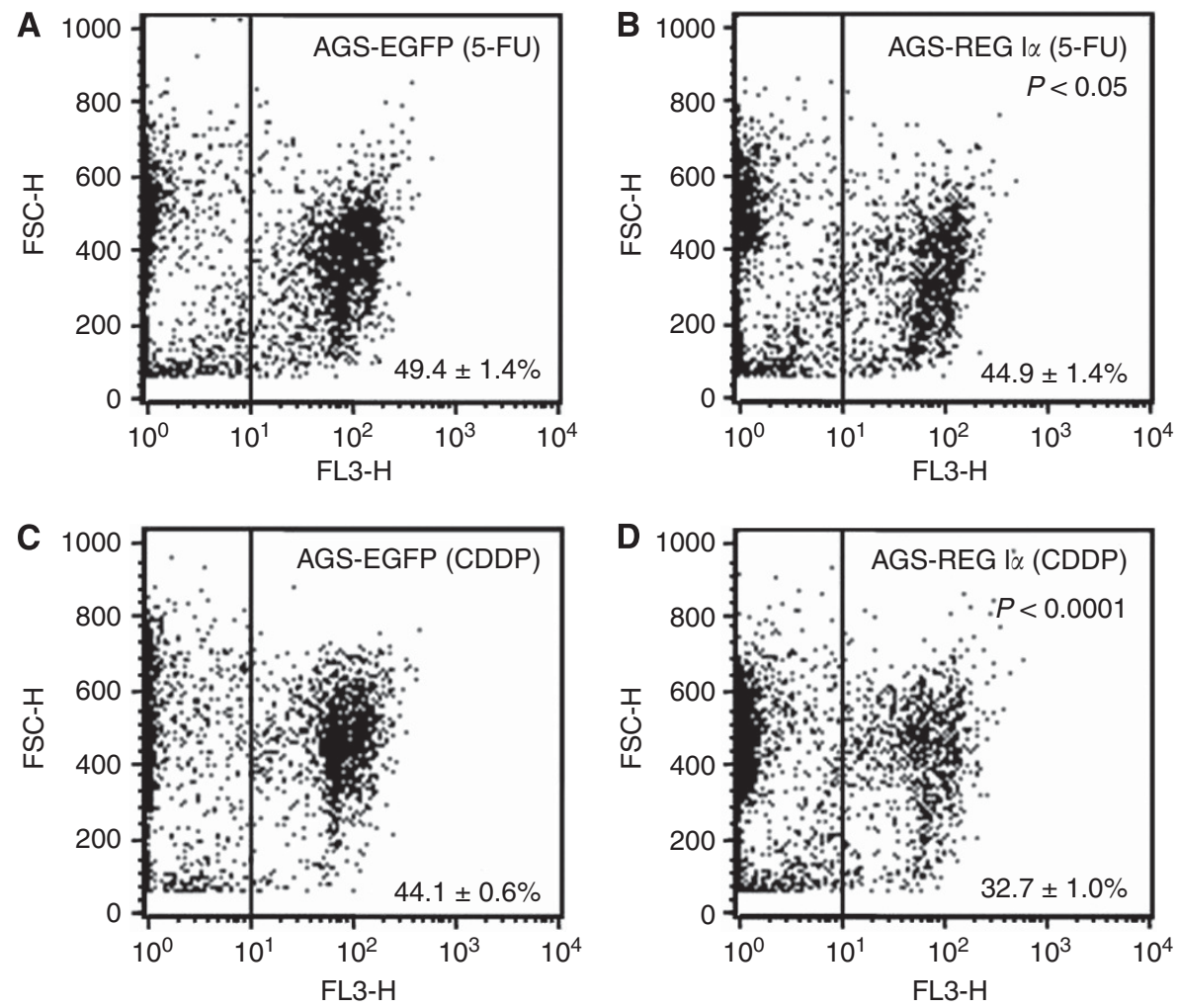

Figure 4. Effects of REG l $\alpha$ gene induction on cell death induced by anticancer drugs in gastric cancer cells. The AGS-REG I $\alpha$ or AGS-EGFP cells were treated with 5-FU (A and B, $20 \mathrm{~mm}$ ) or CDDP (C and D, $100 \mu \mathrm{m})$ for $24 \mathrm{~h}$. The cells were then stained using propidium iodide and analysed by flow cytometry to evaluate the percentage of dead cells, as described in Materials and Methods. All results are expressed as the means \pm s.e.m. of four samples.

patients with unresectable GC. Previously, we and others have suggested that REG I $\alpha$ expression might be applicable as a marker for prediction of OS in GC patients; however, those studies included patients with various stages of GC receiving a variety of treatments (Dhar et al, 2004; Yamagishi et al, 2009). On the other hand, the patients investigated here were homogeneous in terms of both stage and the type of first-line chemotherapy. Although this investigation was designed as historical cohort study, it is tempting to conclude that REG $\mathrm{I} \alpha$ expression has potential promise as a biomarker for predicting the response to S-1/CDDP treatment and subsequent PFS and OS in patients with unresectable GC. Furthermore, it is noteworthy that REG I $\alpha$ expression was examined in biopsy samples before chemotherapy. Numerous molecules have been reported as prognostic markers in GC patients, and supportive evidence has been obtained using mainly surgically resected samples. Although surgical specimens are more suitable than biopsy samples for examining the expression of target molecules, it would be clearly more desirable to examine the presence of predictive biomarkers in samples that can be easily obtained before treatment, such as biopsied tissues. In this context, as demonstrated in the present study, REG I $\alpha$ may be a valuable biomarker for practical assessment of patients with unresectable GC. On the other hand, several studies have suggested that GC patients in high PS score (PS $\geqslant 2$ ) show worse prognosis compared with ones in low PS score $(\mathrm{PS}<2)$ when they were treated with chemotherapy (Chau et al, 2004; Lee et al, 2007). In the present study, we divided the patients into PS0 and PS1-2 groups, because the number of PS2 patients was small $(n=8)$. This may be rationale that we found no relation between prognosis and PS status.

During the follow-up periods, we had a chance to obtain biopsy samples from patients who showed resistance to S-1/CDDP treatment and apparent progression of their disease. Interestingly, we found that some REG $\mathrm{I} \alpha$-negative patients became positive when the first-line chemotherapy failed, implying that GC may begin to express REG $\mathrm{I} \alpha$ during acquisition of resistance to chemotherapy. On the other hand, as GC lesions are not homogeneous in terms of REG I $\alpha$ expression, we cannot exclude the possibility that initial biopsy samples had been accidentally obtained from REG I $\alpha$-negative parts of the lesions. However, like the REG IV gene, it is likely that repeated exposure to cytotoxic chemotherapeutic reagents had induced the expression of the antiapoptotic REG I $\alpha$ gene (Violette et al, 2003). Although our preliminary data need to be reconfirmed in further experiments using a cell-biological approach, REG I $\alpha$ appears to have potential utility as a marker for predicting susceptibility to chemotherapy in patients with unresectable GC.

How, then, does REG I $\alpha$ confer resistance to chemotherapy in GC cells? Previous studies have indicated that activation of the antiapoptotic pathway, overexpression of multidrug transporter proteins, and activation of enzymes capable of metabolising chemotherapeutic drugs are involved in resistance of chemotherapy (Longley et al, 2003; Tsuruo et al, 2003; Matsubara et al, 2008; Zhang et al, 2011). We have previously shown that REG I $\alpha$ exerts its antiapoptotic effect by activating Akt signalling and its downstream Bad phosphorylation and Bcl-xL expression (Sekikawa et al, 2005, 2008), suggesting that REG I $\alpha$ confers resistance to chemotherapy by activating the antiapoptotic pathway in GC cells. In the present in vitro studies, we examined the effect of REG I $\alpha$ gene induction on resistance to 5-FU and CDDP in GC cells. Subsequently, REG I $\alpha$-overexpressing GC cells showed significant resistance to those chemotherapeutic agents in comparison with control GC cells, although the difference between the two groups was not as great as we had expected. Conversely, this finding may be reasonable if REG $I \alpha$ plays a role as only one of several antiapoptotic molecules, and does not activate multidrug 
transporter proteins or chemotherapeutic drug-metabolising enzymes. Clearly, however, further studies will be needed to clarify the mechanism by which REG I $\alpha$ confers resistance to chemotherapy in GC cells.

In summary, we have shown that REG $\mathrm{I} \alpha$ is a potential marker for predicting not only resistance to S-1/CDDP treatment but also the outcome in patients with stage IV GC. Moreover, our in vitro studies have demonstrated that REG I $\alpha$ gene induction confers resistance to the treatment with 5-FU or CDDP in GC cells. In the context of potential clinical application, these data suggest that REG $I \alpha$ could be a target of anticancer therapy, and that its expression would be a useful marker for allocation of individualised chemotherapy.

\section{ACKNOWLEDGEMENTS}

This work was supported in part by grants-in-aid for Scientific Research 23590929 from the Ministry of Education, Culture, Sports, Science and Technology, Japan. We are grateful to Dr Hiroshi Okamoto from Tohoku University Graduate School of Medicine, Sendai, Japan, for providing the anti-REG I $\alpha$ antibody.

\section{CONFLICT OF INTEREST}

The authors declare no conflict of interest.

\section{REFERENCES}

Boku N (2008) Chemotherapy for metastatic gastric cancer in Japan. Int J Oncol 13: 483-487.

Chau I, Norman AR, Cunningham D, Waters JS, Oates J, Ross PJ (2004) Multivariate prognostic factor analysis in locally advanced and metastatic esophago-gastric cancer-pooled analysis from three multicenter, randomized, controlled trials using individual patient data. J Clin Oncol 22: 2395-2403.

Choi IS, Lee HS, Lee KW, Kim H, Kim KH, Kim YJ, Kim JH, Kim WH, Lee JS (2011) Biomarker analysis in patients with advanced gastric cancer treated with S-1 plus cisplatin chemotherapy: orotate phosphoribosyltransferase expression is associated with treatment outcomes. Med Oncol 28: 991-998.

Dhar DK, Udagawa J, Ishihara S, Otani H, Kinoshita Y, Takasawa S, Okamoto H, Kubota H, Fujii T, Tachibana M, Nagasue N (2004) Expression of regenerating gene I in gastric cancer adenocarcinomas. Cancer 100: 1130-1136.

Ferlay J, Shin HR, Bray F, Forman D, Mathers C, Parkin DM (2010) Estimates of worldwide burden of cancer in 2008: GLOBOCAN 2008. Int J Cancer 127: 2893-2917.

Fukui H, Fujii S, Takeda J, Kayahara T, Sekikawa A, Nanakin A, Suzuki K, Hisatsune H, Seno H, Sawada M, Fujimori T, Chiba T (2004) Expression of Reg I $\alpha$ protein in human gastric cancers. Digestion 69: 177-184.

Fukui H, Kinoshita Y, Maekawa T, Okada A, Waki S, Hassan S, Okamoto H, Chiba T (1998) Regenerating gene protein may mediate gastric mucosal proliferation induced by hypergastrinemia in rats. Gastroenterology 115: 1483-1493.

Ichikawa W, Sasaki Y (2006) Correlation between tumor response to first-line chemotherapy and prognosis in advanced gastric cancer patients. Ann Oncol 17: 1665-1672.

Japanese Gastric Cancer Association (1998) Japanese classification of gastric carcinoma, 2nd English edn. Gastric Cancer 1: 10-24.

Kamangar F, Dores GM, Anderson WF (2006) Patterns of cancer incidence, mortality, and prevalence across five continents: defining priorities to reduce cancer disparities in different geographic regions of the world. J Clin Oncol 24: 2137-2150.

Kodera Y, Ito Y, Ohashi N, Nakayama G, Koike M, Fujiwara M, Nakao A (2011) Impact of clinical response to first-line chemotherapy on gastric cancer patients treated with second-line and third-line chemotherapy. Hepatogastroenterology 58: 1041-1045.
Koizumi W, Narahara H, Hara T, Takagane A, Akiya T, Miyashita K, Nishizaki T, Kobayashi O, Takiyama W, Toh Y, Nagaie T, Takagi S, Yamamura Y, Yanaoka K, Orita H, Takeuchi M (2008) S-1 plus cisplatin versus S-1 alone for first-line treatment of advanced gastric cancer (SPIRITS trial): a phase III trial. Lancet Oncol 9: 215-221.

Lee J, Lim T, Uhm JE, Park KW, Park SH, Lee SC, Park JO, Park YS, Lim HY, Sohn TS, Noh JH, Heo JS, Park CK, Kim S, Kang WK (2007) Prognostic model to predict survival following first-line chemotherapy in patients with metastatic gastric adenocarcinoma. Ann Oncol 18: 886-891.

Longley DB, Harkin DP, Johnston PG (2003) 5-Fluorouracil: mechanisms of action and clinical strategies. Nat Rev Cancer 3: 330-338.

Matsubara J, Nishina T, Yamada Y, Moriwaki T, Shimoda T, Kajiwara T, Nakajima TE, Kato K, Hamaguchi T, Shimada Y, Okayama Y, Oka T, Shirao K (2008) Impacts of excision repair cross-complementing gene 1 (ERCC1), dihydropyrimidine dehydrogenase, and epidermal growth factor receptor on the outcomes of patients with advanced gastric cancer. Br J Cancer 98: 832-839.

Ohtsu A (2008) Chemotherapy for metastatic gastric cancer: past, present, and future. J Gastroenterol 43: 256-264.

Park SR, Kong SY, Nam BH, Choi IJ, Kim CG, Lee JY, Cho SJ, Kim YW, Ryu KW, Lee JH, Rhee J, Park YI, Kim NK (2011) CYP2A6 and ERCC1 polymorphisms correlate with efficacy of S-1 plus cisplatin in metastatic gastric cancer patients. Br J Cancer 104: 1126-1134.

Satomura Y, Sawabu N, Ohta H, Watanabe H, Yamakawa O, Motoo Y, Okai T, Toya D, Makino H, Okamoto H (1993) The immunohistochemical evaluation of PSP/reg-protein in normal and diseased human pancreatic tissues. Int J Pancreatol 13: 59-67.

Sekikawa A, Fukui H, Fujii S, Ichikawa K, Tomita S, Imura J, Chiba T, Fujimori T (2008) REG I $\alpha$ protein mediates an anti-apoptotic effect of STAT3 signaling in gastric cancer cells. Carcinogenesis 29: 76-83.

Sekikawa A, Fukui H, Fujii S, Takeda J, Nanakin A, Hisatsune H, Seno H, Takasawa S, Okamoto H, Fujimori T, Chiba T (2005) REG I $\alpha$ protein may function as a trophic and/or anti-apoptotic factor in the development of gastric cancer. Gastroenterology 128: 642-653.

Takaishi S, Wang TC (2007) Gene expression profiling in a mouse model of Helicobacter-induced gastric cancer. Cancer Sci 98: 284-293.

Terazono K, Yamamoto H, Takasawa S, Shiga K, Yonemura Y, Tochino Y, Okamoto H (1988) A novel gene activated in regenerating islets. J Biol Chem 263: 2111-2114.

Therasse P, Arbuck SG, Eisenhauer EA, Wanders J, Kaplan RS, Rubinstein L, Verweij J, Van Glabbeke M, van Oosterom AT, Christian MC, Gwyther SG (2000) New guidelines to evaluate the response to treatment in solid tumors. J Natl Cancer Inst 92: 205-216.

Tsuruo T, Naito M, Tomida A, Fujita N, Mashima T, Sakamoto H, Haga N (2003) Molecular targeting therapy of cancer: drug resistance, apoptosis and survival signal. Cancer Sci 94: 15-21.

Violette S, Festor E, Pandrea-Vasile I, Mitchell V, Adida C, Dussaulx E, Lacorte JM, Chambaz J, Lacasa M, Lesuffleur T (2003) REG IV, a new member of the regenerating gene family, is overexpressed in colorectal carcinomas. Int J Cancer 103: 185-193.

Watanabe T, Yonekura H, Terazono K, Yamamoto H, Okamoto H (1990) Complete nucleotide sequence of human reg gene and its expression in normal and tumoral tissues. J Biol Chem 265: 7432-7439.

Yamagishi H, Fukui H, Sekikawa A, Kono T, Fujii S, Ichikawa K, Tomita S, Imura J, Hiraishi H, Chiba T, Fujimori T (2009) Expression profile of REG family proteins REG I $\alpha$ and REG IV in advanced gastric cancer: comparison with mucin phenotype and prognostic markers. Mod Pathol 22: 906-913.

Yonemura Y, Sakurai S, Yamamoto H, Endou Y, Kawamura T, Bandou E, Elnemr A, Sugiyama K, Sasaki T, Akiyama T, Takasawa S, Okamoto H (2003) REG gene expression is associated with the infiltrating growth of gastric cancer. Cancer 98: 1394-1400.

Zhang J, Roberts TM, Shivdasani RA (2011) Targeting PI3K signaling as a therapeutic approach for colorectal cancer. Gastroenterology 141: 50-61.

This work is published under the standard license to publish agreement. After 12 months the work will become freely available and the license terms will switch to a Creative Commons AttributionNonCommercial-Share Alike 3.0 Unported License. 